\title{
DESIGN, CONSTRUCTION AND PERFORMANCE EVALUATION OF AN ELECTRIC POWERED EGG INCUBATOR
}

\author{
Gbabo Agidi $^{1}$, J.T Liberty ${ }^{2}$, O.N Gunre ${ }^{3}$, G.J Owa ${ }^{4}$ \\ ${ }^{I}$ Department of Agricultural and Bioresources Engineering, Federal University of Technology, Minna, Niger State \\ ${ }^{2}$ Department of Agricultural and Bioresources Engineering, University of Nigeria, Nsukka, Enugu State, Nigeria \\ ${ }^{3}$ Department of Agricultural and Bioresources Engineering, Federal University of Technology, Minna, Niger State \\ ${ }^{4}$ Department of Agricultural and Bioresources Engineering, Federal University of Technology, Minna, Niger State
}

\begin{abstract}
Poultry production is a lucrative business in Nigeria but inadequate hatchery machines limit the expansion and make poultry products for instance day old chicks more expensive. At the moment, few commercially owned poultry hatcheries in Nigeria are located distance far away in the western and Eastern parts of the country. Majority of these hatcheries have little or no access to the national grid system but operate at about 60 per cent below the installation capacity. Generally, environmental pollution, unreliability and lack of access to grid power supply and low performance efficiency characterize the condition of the poultry hatchery business powered by conventional energy supply in Nigeria. These hamper and adversely affect the establishment of medium to large scale poultry production outfits in the rural areas of the country. But with the advent of electric powered egg incubator technology in poultry production, poultry farmers in Nigeria are likely to incubate and hatch poultry eggs and breed day-old chicks under a sustained power supply in a clean environment. Therefore, this study was aimed at the design, developed and tested in order to provide a favourable environment for eggs hatching. The developed machine was tested to assess its performance. The results from the test showed that out of the total 25 eggs, 5 eggs hatched after operating the machine. This gives 33\% hatchability. The results showed that with further improvements, the developed machine can adequately be adopted at the household level instead of rearing chickens for the sole purpose of incubating eggs.
\end{abstract}

Keywords: Automatic, egg turning incubator, favourable environment, hatchability $* * *$

\section{INTRODUCTION}

In poultry egg incubation, sustainable energy supply is necessary for efficient performance, operation and profitability. This involves the management of fertilized poultry eggs to a satisfactory development level that leads to normal chicks (Oluyemi, 1979). It includes the control of the extrinsic environmental factors of the surrounding.

The mother hen naturally performs this function but at low efficiency (French, 1997). And artificially, an incubator, a special system that simulates the environmental conditions required for such operation is usually employed by poultry farmers to do the same operation within specified temperature and relative humidity range. The ranges are usually between temperature and relative humidity of between $36-390 \mathrm{C}$ and $50-70 \%$ respectively. To maintain this temperature range sustained heat supply is paramount. In the most developing countries, the vast majority of poultry farmers in the rural communities operate their farms on small scale and/or even subsistence level. They often use a collection of bush lamps and kerosene stoves to achieve the heating requirements of the small hatcheries and brooders for day-old chicks (Okonkwo, 1989). The problems with these systems are enormous ranging from environmental pollution and fire outbreak. Use of fossil fuel is known to produce toxic gases which are harmful to eggs and poultry attendants. However, an electric egg incubator will produce clean energy without harmful effects on the environment. Therefore, this study aimed at the design, construction and performance evaluation of an electric egg incubator is timely as it will encourage and facilitate poultry egg production in the country.

\section{MATERIALS AND METHODS}

The following materials were used in the development of the egg incubator: plywood, fan, thermostat, heating element, wet and dry bulb thermometer, relays, piece of glass, wires, shaft, top bond glue, electric motor, paint, bolts and nuts, transformer, and bearings.

\subsection{Design Calculations}

The incubator design calculations were based on the conditions required for the machine to work effectively. Some of the conditions were the temperature of the incubator which was to be maintained, relative humidity and the turning mechanism which turns the eggs at-least three times a day. It 
was also based on design considerations such as materials selection, standards and required parameters.

\subsection{Capacity of the Incubator Egg Tray}

Major diameter of an egg $=60 \mathrm{~mm}$

Minor diameter $=46 \mathrm{~mm}$

Border end $=24 \mathrm{~mm}$

Volume of the egg tray can be estimated;

$=\frac{\pi x D^{2} x H x n}{4}$ Where,

$\mathrm{V}=$ volume of the egg tay $\left(\mathrm{m}^{3}\right)$

$\mathrm{D}=$ minor diameter $=0.046 \mathrm{~m}$

$\mathrm{H}=$ height of the egg tray or minor diameter $=0.06 \mathrm{~m}$

$\mathrm{n}=$ number of eggs on an egg tray $=25$

$V=\frac{n x \pi x D^{2} x H}{4}=\frac{25 x \pi x 0.046^{2} x 0.06}{4}$

$=\frac{25 \times \pi \times 0.002116 \times 0.06}{4}=\frac{0.00997}{4}=0.0025 \mathrm{~m}^{3}$

The egg tray was rectangular in shape with a height of $60 \mathrm{~mm}$. the volume of the tray can be calculated as;

$V=L x B x H$ Where,

$\mathrm{L}=$ length of the egg tray $(\mathrm{m})$

$\mathrm{B}=$ breadth and $\mathrm{H}=$ height $=0.06 \mathrm{~m}$

Let the length of the two trays be twice breadth of egg tray of the incubator;

$$
L=2 x B, V=L x B x H
$$

Substituting for $\mathrm{L}$ in the equation

$V=2 x B x B x H=2 x B^{2} x H$

$B^{2}=\frac{V}{2 x H}=\frac{0.0025}{2 x 0.06}=\frac{0.0025}{0.12}$

$B=\sqrt{0.0208}=0.144 m$

Therefore, $L=2 \times B=2 \times 0.144=0.288 \mathrm{~m}$

The dimension of the tray was $0.288 \times 0.144 \times 0.06 \mathrm{~m}$

\subsection{Volume of Air in the Incubator}

Thickness of plywood $=15 \mathrm{~mm}$

$V=L x B x H$ Where,

$\mathrm{V}=$ volume of the incubator cabinet $\left(\mathrm{m}^{3}\right)$
$\mathrm{L}=$ length of the incubator $=0.41 \mathrm{~m}$

$\mathrm{B}=$ breadth $=0.32 \mathrm{~m}$, height $=0.60 \mathrm{~m}$

$V=0.41 \times 0.32 \times 0.60=0.0787 \mathrm{~m}^{3}$

The volume of air in the incubator $=0.0787 \mathrm{~m}^{3}$

\subsection{Determination of the Mass of Air $\left(M_{a}\right)$}

$$
\rho_{a}=\frac{m_{a}}{V}
$$

Where

$\rho_{\mathrm{a}}=$ density of air $=1.23 \mathrm{~kg} / \mathrm{m}^{3}$ (Rajput, 1998)

$\mathrm{M}_{\mathrm{a}}=$ mass of air $(\mathrm{kg})$

$\mathrm{V}=$ volume of air in the incubator cabinet $=0.0787 \mathrm{~m}^{3}$

$\rho_{a}=\frac{M_{a}}{V}, M_{a}=\rho_{a} x V=1.23 \times 0.0787=0.097 \mathrm{~kg}$

The required mass of air was $0.097 \mathrm{~kg}$

\subsection{Determination of the Amount of Heat Energy in the Incubator}

This calculation was done in order to determine the quantity of electric heat energy suitable to incubate the required number of eggs. This is the sum of the expected heat loss through the walls of the incubator, insulator and the actual heat required for incubation. It was based on the temperature ranges needed by the incubator $\left(37-39^{\circ} \mathrm{C}\right)$. It was therefore calculated by the difference between the room temperature $\left(25^{\circ} \mathrm{C}\right)$ and optimum temperature of the incubator $939\left({ }^{0} \mathrm{C}\right)$.

$$
Q=M_{p} x C_{p p}+M_{a} x C_{p a} x\left(T_{2}-T_{1}\right)
$$

Where

$\mathrm{Q}=$ heat required by the incubator $(\mathrm{J})$

$\mathrm{M}_{\mathrm{p}}=$ mass of plywood $=42.50 \mathrm{~kg}$

$\mathrm{C}_{\mathrm{pp}}=$ specific heat capacity of the plywood $=1210 \mathrm{~J} / \mathrm{kgk}$

$\mathrm{M}_{\mathrm{a}}=$ mass of air $=0.097 \mathrm{~kg}$

$\mathrm{C}_{\mathrm{pa}}=$ specific capacity of air $=1005 \mathrm{~J} / \mathrm{kgk}($ Eastop, 1993)

$\mathrm{T}_{1}=$ room temperature $=25^{\circ} \mathrm{C}$

$\mathrm{T}_{2}=$ optimum temperature of the incubator $=39^{\circ} \mathrm{C}$

$$
\begin{aligned}
& \therefore Q=42.5 \times 1210 \times 0.097 \times 1005 \times(39-25) \\
& =51425+97.49(4)=721314.86 J
\end{aligned}
$$

\subsection{Power Requirement by the Incubator}

The power supply by the heating element was determined for a period of 24 hours.

$$
Q=P x t ; P=\frac{Q}{t}
$$


Where

$\mathrm{Q}=$ heat energy required by the incubator $=721314.86 \mathrm{~J}$

$\mathrm{P}=$ electric power to be supplied by the heating element $(\mathrm{W})$

$\mathrm{t}=$ time $=24 \times 60 \times 60$

$$
P=\frac{721314.86}{24 \times 60 \times 60}=\frac{721314.86}{86400}=8.35 \mathrm{~W} \approx 8.0 \mathrm{~W}
$$

The power to be supplied by the heating element everyday was $8 \mathrm{~W}$ for the incubator temperature to be maintained at $39^{\circ} \mathrm{C}$

\subsection{Design of the Ventilation Holes}

The ventilation heat loss to the environment of the incubator was given by;

$Q_{v}=C x V_{e} x\left(T_{2}-T_{1}\right) ; V_{e}=\frac{Q_{v}}{C x\left(T_{2}-T_{1}\right)}$

Where

$\mathrm{Q}_{\mathrm{v}}=$ heat loss per hour $=8.35 \mathrm{~J} / \mathrm{s}$

$\mathrm{C}=$ specific heat capacity of air $=1300 \mathrm{~J} / \mathrm{kg}^{0} \mathrm{C}$ (Eastop, 1993)

$\mathrm{V}_{\mathrm{e}}=$ ventilation rate $\left(\mathrm{m}^{3} / \mathrm{s}\right)$

$\mathrm{T}_{1}=$ room temperature $=25^{0} \mathrm{C}$

$\mathrm{T}_{2}=$ optimum temperature of the incubator $=39^{\circ} \mathrm{C}$ (Wilson, 2002)

$\therefore V_{e}=\frac{8.35}{1300 \times(39-25)}=\frac{8.35}{1300 \times 14}=\frac{8.35}{18200}=0.00046 \mathrm{~m}^{3} / \mathrm{s}$

The ventilation rate was $0.0046 \mathrm{~m}^{3} / \mathrm{s}$

$V_{e}=A x S ; A=\frac{V_{e}}{S}$ Where

$\mathrm{V}_{\mathrm{e}}=$ ventilation rate (flow rate) $=0.0046 \mathrm{~m}^{3} / \mathrm{s}$

$\mathrm{A}=$ area of the hole $\left(\mathrm{m}^{2}\right)$

$\mathrm{S}=$ air velocity $=2 \mathrm{~m} / \mathrm{s}$

$\therefore A=\frac{0.00046}{2}=0.00023 \mathrm{~m}^{2}$

The area of the ventilation hole $=2.3 \mathrm{~cm}^{2}$

\subsection{Area of the Egg Tray}

$$
A=L x B
$$

Where

$A=$ area of the tray $\left(\mathrm{m}^{2}\right)$

$\mathrm{L}=$ length of the egg tray $=0.288 \mathrm{~m}$
$\mathrm{B}=$ breadth of the egg tray $=0.144 \mathrm{~m}$

$A=0.288 \times 0.144=0.0415 m^{2}$

\subsection{Design of the Egg Turning Mechanism}

Regular turning of eggs an angle of $45^{\circ} \mathrm{C}$ was crucial or successful hatching of the eggs. Turning prevents embryo from sticking to the shell membranes.

$$
L=\frac{\theta x 2 x \pi x r}{360}
$$

Where

$\mathrm{L}=$ length of an $\operatorname{arc}(\mathrm{m})$

$\theta=$ angle of turn $=45^{\circ} \mathrm{C}$

$\mathrm{r}=$ radius of the egg tray $=\frac{0.144}{2}=0.07 \mathrm{~m}$

$$
L=\frac{45 \times 2 \times \pi \times 0.07}{360}=\frac{90 \times \pi \times 0.07}{360}=\frac{19.79}{360}=0.05 \mathrm{~m}
$$

\subsection{Heat Loss at Opposite Sides of the Incubator}

The heat loss at opposite sides of the incubator could be calculated because of their equal surface areas and also made up of the same material (plywood).

$$
\begin{aligned}
& \text { Area } A=L x B=0.8 x 0.35=0.28 \mathrm{~m}^{2} \\
& \qquad q=\frac{A x K x\left(T_{2}-T_{1}\right)}{L}=\frac{0.28 x 0.12 x(311-298)}{0.015} \\
& =\frac{0.4368}{0.015}=29.12 \mathrm{~W}
\end{aligned}
$$

But it was two opposite surfaces;

$$
\therefore q=29.12 \times 2=58.24 \mathrm{~W}
$$

\subsection{Heat Loss at the Top and Bottom Surfaces of the}

\section{Incubator}

The top and bottom surfaces of the incubator were equal and opposite made of the same material.

$$
\text { Area, } A=L x B=0.44 x 0.35=0.154 m^{2}
$$

Since there were two equal surfaces, $A=2 \times 0.154 \mathrm{~m}^{2}$ 
Then,

$$
\begin{aligned}
& q=\frac{A x K x\left(T_{2}-T_{1}\right)}{L}=\frac{0.308 \times 0.12 x(311-298)}{0.015} \\
& =\frac{0.308 x 0.12 \times 13}{0.015}=\frac{0.48048}{0.015}=32.03 \mathrm{~W}
\end{aligned}
$$

\subsection{Heat Loss at the Front and Back of the} Incubator

$$
\begin{gathered}
\text { Area, } A=L x B=0.8 \times 0.44=0.352 \mathrm{~m}^{2} \\
q=\frac{A x K x\left(T_{2}-T_{1}\right)}{L}=\frac{0.352 \times 0.12 \times(311-298)}{0.015} \\
=\frac{0.352 \times 0.12 \times 13}{0.015}=\frac{0.054912}{0.015}=36.61 \mathrm{~W}
\end{gathered}
$$

The area of the incubator front made of plywood was equal to the surface area of the incubator front minus the area covered by glass $\left(\mathrm{A}_{\mathrm{g}}\right)$

$$
\begin{gathered}
=L_{g} x B_{g}=0.40 x 0.10=0.04 m^{2} \\
q_{q}=\frac{A_{g} x K_{g} x\left(T_{2}-T_{2}\right)}{L_{g}}
\end{gathered}
$$

Where

$\mathrm{q}_{\mathrm{g}}=$ rate of heat loss by glass $(\mathrm{W})$

$\mathrm{K}_{\mathrm{g}}=$ thermal conductivity of the glass $=0.096 \mathrm{~W} / \mathrm{k}$

$\mathrm{T}_{2}=$ temperature of the incubator $=273+38=311 \mathrm{k}$

$\mathrm{T}_{1}=$ room temperature $=273+25=298 \mathrm{k}$

$\mathrm{L}_{\mathrm{g}}=$ thickness of the glass $=0.015 \mathrm{~m}$

$q=\frac{0.04 \times 0.96 \times(311-298)}{0.015}=\frac{0.04 \times 0.96 \times 13}{0.015}$

$=\frac{0.4992}{0.015}=33.28 \mathrm{~W}$

The area of the incubator front

$$
A_{T}=L x B
$$

Where $\mathrm{A}_{\mathrm{T}}=$ area of the front $\left(\mathrm{m}^{2}\right)$

$\mathrm{L}=$ length of the front surface $=0.80 \mathrm{~m}$

$\mathrm{B}=$ breadth of the front surface $=0.44 \mathrm{~m}$

$$
A_{T}=L x B=0.8 x 0.44=0.352 m^{2}
$$

The area of plywood

$$
\begin{gathered}
A=A_{T}-A_{g}=0.352-0.04=0.312 \mathrm{~m}^{2} \\
q=\frac{A x K x\left(T_{2}-T_{1}\right)}{L}=\frac{0.312 \times 0.12 x(311-298)}{0.015} \\
=\frac{0.312 \times 0.12 \times 13}{0.015}=\frac{0.48672}{0.015}=32.45 \mathrm{~W}
\end{gathered}
$$

Heat loss is the summation of all calculated heat around the incubator.

Total heat loss at both sides opposite sides of the incubator $=$ $58.24 \mathrm{~W}$

Total heat loss at the top and bottom surfaces of the incubator $=32.03$

Heat loss at the back of the incubator $=36.61 \mathrm{~W}$

Heat loss from glass at the front $=32.28 \mathrm{~W}$

Heat loss from plywood at the front $=32.45 \mathrm{~W}$

Therefore, heat losses $=58.24+32.03+36.61+33.28+32.45=$ 192.61W

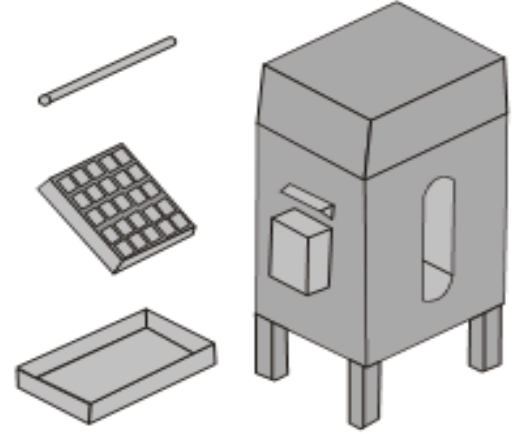

Fig1: Isometric view of the egg incubator

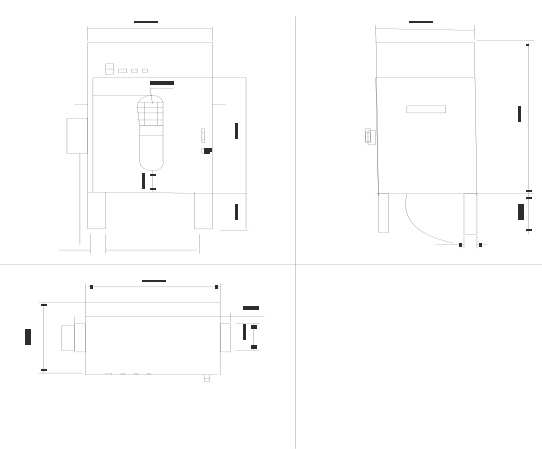

Fig 2: Orthographic view of the Egg Incubator 


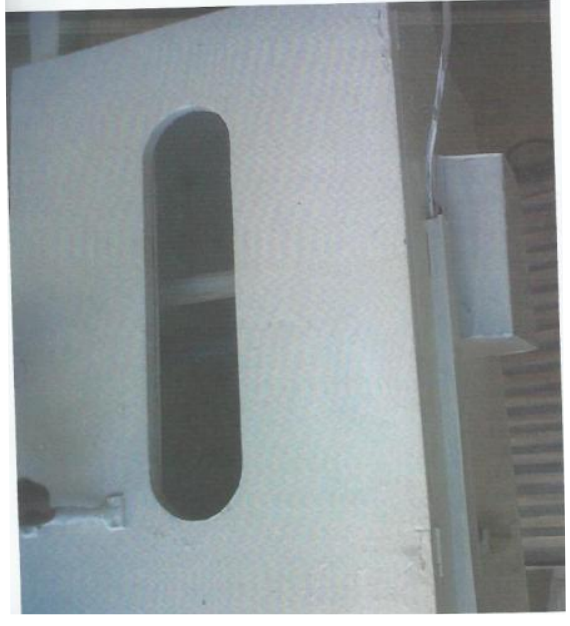

Fig3: The Constructed Egg Incubator

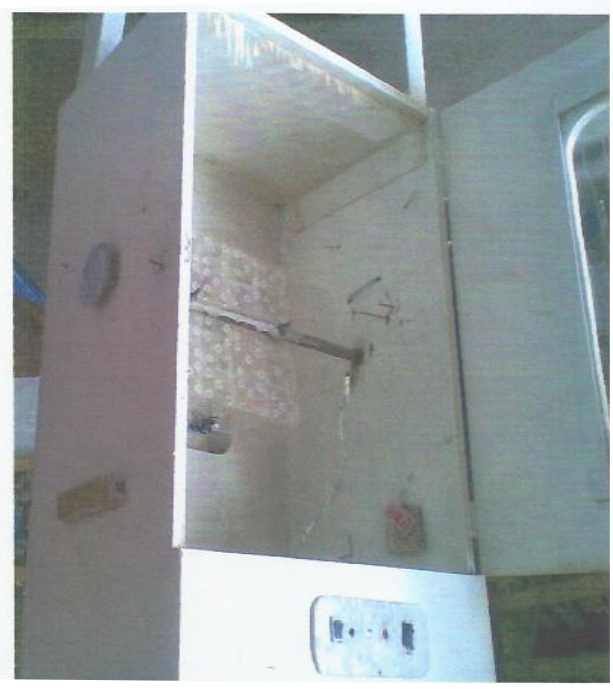

Fig 4: Interior view of Egg Incubator

\section{RESULTS AND DISCUSSION}

Percentage fertility $=\frac{\text { Number of fertile eggs }}{\text { Number of eggs in the incubator }} \times 100$

$$
=\frac{15 \times 100}{25}=\frac{1500}{25}=60 \%
$$

Percentage hatchability $=\frac{\text { Number of eggs that hatched out }}{\text { Number of fertile eggs }} \times 100$

$=\frac{5 \times 100}{15}=\frac{500}{15}=33 \%$
Twenty five eggs were kept inside the incubator over a period of 21 days. The relative humidity, temperature and turning of eggs were maintained throughout the incubation period. The following were the observations recorded;

Number of fertile eggs $=15$

Number of eggs that hatched out $=5$

\section{CONCLUSIONS AND RECOMMENDATION}

This work focused which on the design, construction and performance evaluation of an automatic turning mechanism egg incubator was of less energy consuming and does not require continual presence of the operator. The machine will boost poultry farming in the country and beyond. The percentage hatchability of the incubator was 33\%. The incubator functioned as expected. However, the following recommendations are worthy of note for further research:

i. Incubator for other eggs such as turkey egg should be worked on so as to provide compressive information's for the design of incubators.

ii. Motor with lower rating should be used to avoid high turning speed.

iii. There's need for a constant supply of electricity to enable unobstructed operation of the incubator.

\section{REFERENCES}

[1]. J. A Oluyemi and F. A. Roberts. Poultry Production in Warm Climates The Macmillan Publishers Limited, London and Basingstoke. 1979.

[2]. N. A. French. Modeling Incubation Temperature: The Effect of Incubator Design, Embryonic Development, and Egg Size Poult Sci. 1997, 76:124-133

[3]. W. I. Okonkwo. Design of solar Energy Egg Incubator Unplished undergraduate project, Department of Agricultural Engineering, University of Agriculture, Makurdi, Nigeria 1989

\section{BIOGRAPHIES:}

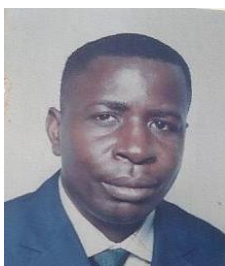

Dr. Gbabo Agidi, a native of Korokorosei, Bayelsa State, Nigeria, obtained a B.Eng degree from University of Science and Technology, Port Harcourt, Rivers State, Nigeria in 1987, M.Eng and $\mathrm{PhD}$ degree from University of Ibadan, Nigeria, 1991 and 2002 respectively. His major area of specialization is Farm Power and Machinery. He is presently an Assistant Director and Head, Agric. Engineering and Mechanization, National Cereals Research Institute, Badeggi and also Senior Lecturer (visiting), Federal University of Technology, Minna, Niger State, Nigeria. Some of his other administrative responsibilities include; Department Head of Agricultural Mechanization Task Force for Africa in Nigeria, Principal Investigator for the Korea Africa Food and Agriculture Corporation Initiative (KAFACI) Project on 
Development of a modified Rice Processing set of Machinery to enhance Rice Productivity in Nigeria, Member of the Task Force Team of the West Africa Agricultural Productivity Project (WAAPP) in Nigeria on Agricultural Mechanization in West Africa. He is a member of the Nigerian Society of Engineers, American Society of Agricultural Engineers (AMASAE), Nigerian Soya-bean Association (MNSA), International Association of Professionals in Sugar and Integrated Technologies IAPSIT and Society for Sugar Research and promotion, India.

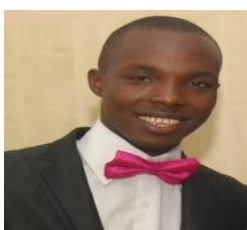

Jacob Tizhe Liberty hails from Michika Local Government Area of Adamawa State, Nigeria. He holds a B.Eng degree in Agricultural and Environmental Resources Engineering from University of Maiduguri, Borno State in the year 2010 and M.Eng degree in Food and Bioprocess Engineering from University of Nigeria, Nsukka, Enugu State, Nigeria. 